\title{
Use of Artificial Neural Networks for Prediction of the Convective Heat Transfer Coefficient in Evaporative Mini-Tubes
}

\section{Uso de redes neuronales para la predicción del coeficiente de transferencia de calor por convección de la evaporacion en minitubos}

\author{
Romero-Méndez Ricardo \\ Universidad Autónoma de San Luis Potosí \\ Faculty of Engineering \\ E-mail:rromerom@uaslp.mx \\ Lara-Vázquez Patricia \\ Universidad Tecnológica de San Luis Potosí \\ E-mail:patylarav@gmail.com. \\ Oviedo-Tolentino Francisco \\ Universidad Autónoma de San Luis Potosí \\ Faculty of Engineering \\ E-mail:francisco.oviedo@uaslp.mx
}

\author{
Durán-García Héctor Martín \\ Universidad Autónoma de San Luis Potosí \\ E-mail:hduran@uaslp.mx \\ Pérez-Gutiérrez Francisco Gerardo \\ Universidad Autónoma de San Luis Potosí \\ Faculty of Engineering \\ E-mail:francisco.perez@uaslp.mx \\ Pacheco-Vega Arturo \\ California State University, Los Angeles \\ Department of Mechanical Engineering \\ E-mail:apacheco@calstatela.edu
}

Information on the article: received: August 2014, accepted: August 2015

\begin{abstract}
In this work, artificial neural networks (ANNs) are used to characterize the convective heat transfer rate that occurs during the evaporation of a refrigerant flowing inside tubes of very small diameter. An experimental setup based on an inverse Rankine refrigeration cycle is used to obtain the heat transfer data in an R-134a refrigerant mini-tube evaporator set operated under constant heat flux conditions. A considerable amount of data was acquired to map the thermal performance of the evaporative process under analysis, $75 \%$ of which were used for training the ANN and 25\% were reserved for prediction purposes. Several neural network configurations were trained and the most accurate was selected to predict the thermal behavior. The results obtained in this investigation reveal the convenience of using ANNs as an accurate predictive tool for determination of convective heat transfer rates inside mini-tube evaporators.
\end{abstract}

\section{Keywords:}

- artificial neural networks

- thermal systems

- compact evaporators

- mini-tubes

- convective heat transfer 


\section{Resumen}

En esta investigación se utilizan redes neuronales para determinar la tasa de transferencia de calor convectiva durante la evaporación de un refrigerante en el interior de un minitubo. Se desarrolló un sistema experimental, incluye un ciclo de refrigeración basado en el ciclo de Rankine inverso, instrumentado con equipo de medición y un sistema de adquisición de datos para obtener información del desempeño térmico bajo diferentes condiciones de operación. Con este banco de pruebas experimental fue posible obtener una cantidad considerable de datos que permiten caracterizar el desempeño térmico del proceso de evaporación en consideración. Un $75 \%$ de las mediciones se usan para entrenar varias configuraciones de red neuronal y $25 \%$ de los datos se emplean para determinar el error de predicción de cada configuración. Los resultados obtenidos en esta investigación demuestran la conveniencia de usar redes neuronales artificiales para la determinación correcta de la transferencia de calor evaporadores de minitubos.

\section{Introduction}

Recent developments of high performance electronic equipment have led to a general reduction of spacing and increase in power. This fact has created a need for efficient heat dissipation. In response to this demand, miniature-size compact heat exchangers with capacity to operate as efficient heat sinks have been recently developed. The reduction of channel size is now a reality and mini-tubes with hydraulic diameters from $200 \mu \mathrm{m}$ to $3 \mathrm{~mm}$ are commonly used. The problem, however, is that the heat transfer and pressure drop in this kind of systems may be significantly different from what has been reported in conventional size evaporators, and there is a lack of reliable information about the thermal performance of these devices.

Much of the progress of heat transfer has been driven by the necessity to predict the performance of a thermal system, which results from applications of fundamental laws (mass, momentum, and energy conservation) for basic problems, supplemented with empirical correlations for more complex cases (complexities stemming from system geometry, flow conditions and appearance of simultaneous heat transfer mechanisms). Unfortunately, there are critical applications related to energy efficiency, environmental impact, optimal system design and control, where traditional techniques fail to provide an adequate prediction and more advanced prediction methods are required. While the thermal sciences must continue to gradually increase knowledge and insight of fundamental phenomena, there are some new technologies, such as artificial neural networks (ANNs) that can be used as application tools to supplement such understanding. This is particularly true in the case of complex flow situations occu- rring in novel applications, such as the cooling of electronic devices with miniature size evaporators.

Heat transfer prediction of condensation and evaporation processes in refrigeration and air conditioning units is a complex task when compared to the prediction of single phase heat transfer. Traditional powerlaw correlations have proved to be inaccurate for this kind of processes, even though there is a need of good predictions in these applications. For instance, using their correlation for forced convective boiling, Gungor and Winterton (1986) obtained errors of $21.4 \%$ for saturated boiling and $25 \%$ for sub-cooled boiling with respect to their own measurements. Years later, it was shown that when experimental data from other authors are used, the errors from this and other correlations can be as large as $50 \%$. The process of phase change in pipes undergoes a series of flow regimes, which go from single phase flow, onset of bubble formation, annular flow boiling, film boiling, mist flow and superheated vapor flow, depending on mass flow rate, degree of superheating, pressure, tube diameter, orientation and vapor quality. All these phenomena occur over a short pipe length. The inability of power-law correlations to catch up with all these phenomena occurring during two phase convection lies as the reason for the inaccuracy of the predictions.

One of the modern technologies that have been successful as an analysis tool is the technique of artificial neural networks (ANNs). This technique has been applied for pattern recognition, decision making, control systems, information processing, symbolic mathematics, computer vision and robotics. The use of ANNs has been extended to a wide variety of disciplines, among which are the thermal sciences, because it allows the study of complex thermal systems that otherwise 
would be impossible to characterize with conventional analysis techniques, since they offer an alternative approach for experimental data compression. ANNs have been used for the prediction of heat transfer coefficients (Jambunathan et al., 1996), the calculation of Nusselt numbers (Thibault and Grandjean, 1991), the prediction of heat transfer in heat exchangers (Díaz et al., 1999; Pacheco-Vega et al., 2001a, 2001b), the estimation of heat transfer in the transition region of a circular tube (Ghajar et al., 2004), to study the thermal performance of cooling towers (Islamoglu, 2005), to analyze phase change in finned tubes (Ermis et al., 2007), to compute friction and heat transfer in helically-finned tubes (Zdaniuk et al., 2007), to model evaporative air coolers (Hosoz et al., 2008), finned-tube condensers (Zhao and Zhang, 2010), finned-tube evaporators (Zhao et al., 2010), and indirect evaporative cooling (Kiran and Rajput, 2011). One of the main advantages of ANNs is that they do not require a detailed knowledge of the physical phenomena describing the system under analysis.

The objective of this work is to use ANNs to characterize the convective heat transfer rate occurring during the evaporation of a refrigerant flowing inside tubes of very small diameter. For this purpose, an experimental setup of a mini-tube evaporator with a constant heat flux condition is first built and instrumented. Next, the experimental apparatus is used to acquire the measurements necessary to map the thermal performance of the evaporative process inside a bundle of mini-tubes as functions of flow and thermal operating conditions and geometrical parameters. Finally, using the experimental data, several neural network configurations are trained and the most accurate was selected to predict the thermal behavior of the mini-tube evaporator. The results reveal that ANNs are accurate predictive tool for the analysis of complex systems such as mini-tube evaporators.

\section{Artificial neural networks}

The theory under which ANNs work is based on the structure and functionality of biological neural systems, where the neuron is the fundamental element. The biological neuron, schematically shown in Figure 1, is formed by the body of the cell, an axon and a series of dendrites. The axon transports the incoming signal from a neuron to other neurons, whereas the dendrites provide enough surface area to facilitate connectivity with other neurons. ANNs have nodes (or artificial neurons), as shown in Figure 2, whose function is to make mapping operations between inputs and outputs. This mapping is usually done by means of a sigmoidal function, although other functions (e.g.: hyperbolic tangent or Gaussian) have also been successfully applied. These artificial neurons are connected to others through linkages of the type axon-synapsis-dendrite, each associated with a weight. As in the case of a biological synapsis, this weight determines the nature and intensity of the influence of a node on another. A weight of large value (either positive or negative) corresponds to a large excitation, while a small weight corresponds to a negligible one. There exist different neural network configurations, the fully-connected being the most common in the analysis of engineering problems. This type of ANN, also called multilayered perceptron or feed-forward network, is shown schematically in Figure 3. It has a series of layers, each formed by a set of nodes; the first layer is called input layer; the last one is the output layer, and the inner layers are known as hidden layers. The network configuration shown in the figure is referred to as fully-connected since each node of a layer is connected to all the nodes of adjacent layers.

To build an artificial neural network model, a training process must be carried out first. This process is accomplished by adjusting the synaptic weights and biases when the different values of input and output variables are supplied to the network. The technique for training the ANN is that of back propagation, described by Rumelhart et al. (1986). After the network configuration has been chosen, the first step of the algorithm is to randomly assign initial synaptic weights and biases. The second step, known as feed-forward step, starts by feeding the data onto the first layer (input layer). The information resulting from the input-output sigmoidal mapping at each node of the inner layers is then transferred forward until it reaches the nodes of the last layer (output layer), where the outputs from the network are compared with the experimental data, and their differences are used later to adjust the corresponding weights. This step is known as back-propagation. In it, the error generated from the feed-forward phase is quantified in each layer and each node by means of a

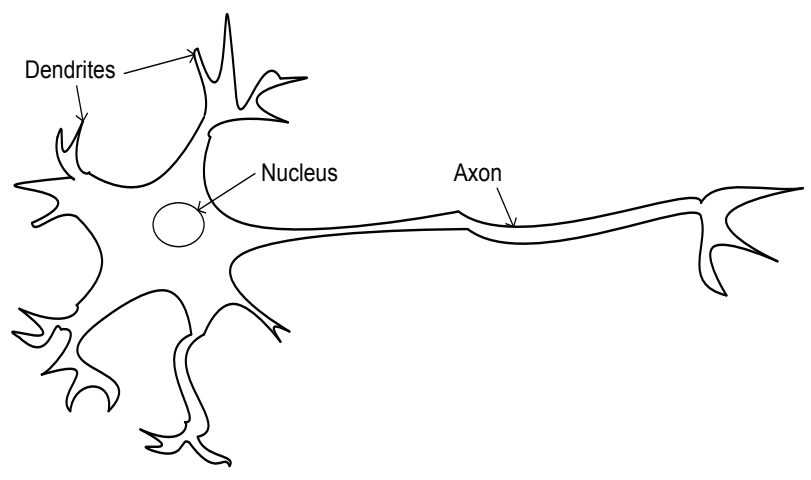

Figure 1. Schematic of a biological neuron 
delta rule and propagated backwards to change the synaptic weights and biases. A feed-forward step followed by a back-propagation one comprises a cycle. The training process ends when the error in the last cycle decreases below an established threshold value.

\section{Experimental setup and procedure}

Experimental set up

An experimental apparatus based on the inverse Rankine cycle, which includes a test section for evaporation of a refrigerant inside a set of mini-tubes, was built and instrumented. The test bench is shown schematically in Figure 4. It has two fluid circuits: one for the refrigerant $\mathrm{R}-134 \mathrm{a}$ and one for cooling water. The refrigerant cir- cuit incorporates a refrigerant pump (RP), a pre evaporator (PE), an evaporator test section (TS), an expansion valve (EV), a double pipe condenser (DC) and sub-cooler (SC) -in which the refrigerant flows inside the annular section while chilled water flows inside the circular pipe- an accumulator tank (AT), a flow meter (FM), a dryer filter (DF) and several peepholes (PH). This circuit starts in the container (CO) and refrigerant flows toward the pump. This is a $1 / 13 \mathrm{HP}$ rotary positive-displacement type pump with external gears, magnetic coupling, and provides volumetric flow rates from 4 to $458 \mathrm{l} / \mathrm{h}$. The pump circulates the refrigerant through a Coriolis-type flow meter, which measures mass flow rates from 0 to 65 $\mathrm{kg} / \mathrm{h}$, densities from 0.1 to $2.9 \mathrm{~g} / \mathrm{cm}^{3}$, and temperatures from $-50^{\circ} \mathrm{C}$ to $180^{\circ} \mathrm{C}$. After the flow meter the refrigerant flows to a pre-evaporator, leaving it at the specific
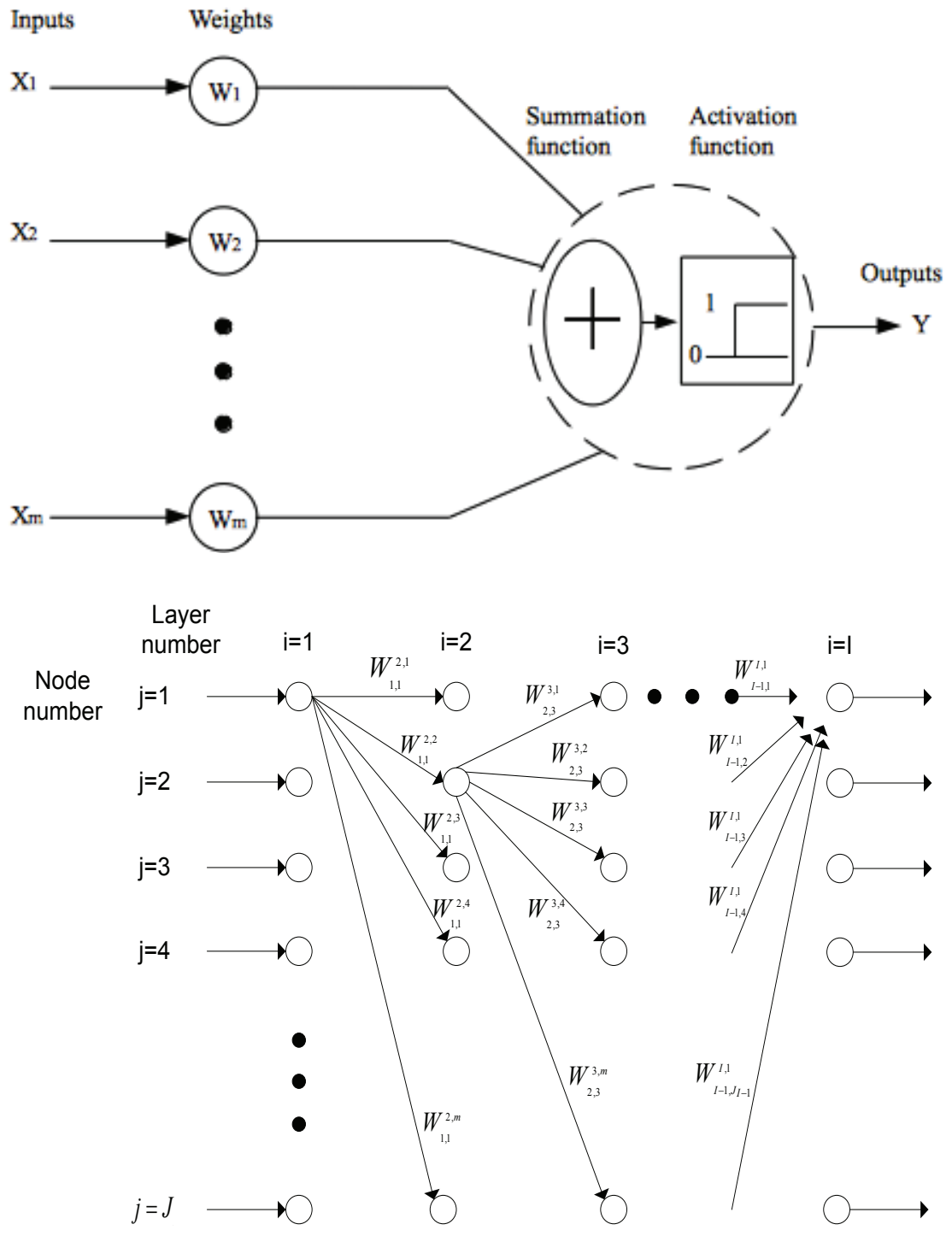

Figure 2. Typical structure of an artificial neuron

Figure 3. A fully-connected artificial neural network configuration 

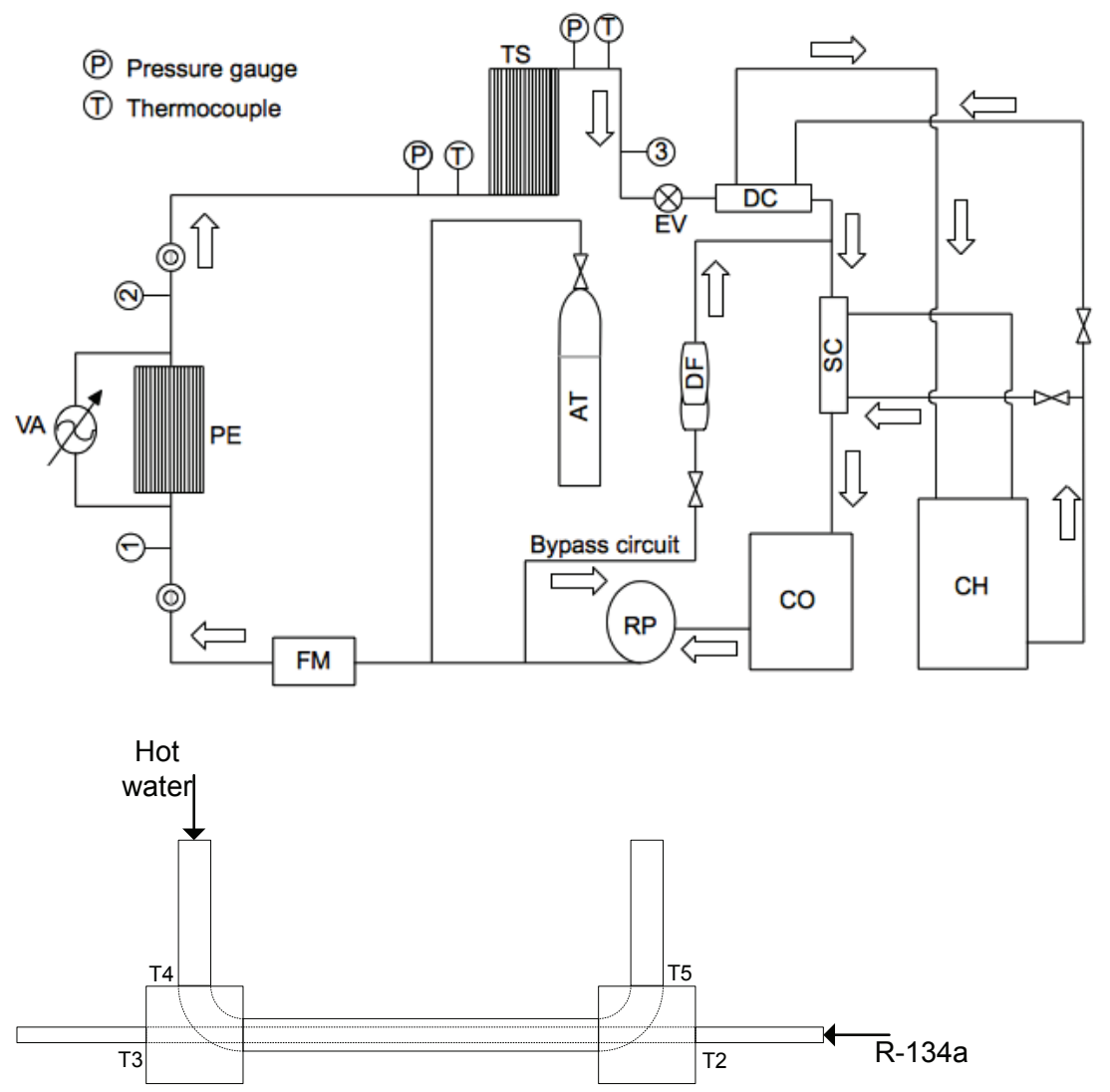

Figure 4. Schematic diagram of the experimental equipment

Figure 5. Schematic diagram of condenser and sub-cooler vapor quality required at the entrance of the evaporator test section.

This experimental setup has an electrical resistance through which the power is supplied to the system that is controlled by means of a variable autotransformer. Both the pre-evaporator and the test section have similar designs (see description below). Once the refrigerant is pre-heated, it is circulated through the evaporator test section, where it evaporates and the required measurements for the present study are collected. After passing an expansion valve, a condenser and a subcooler are used to treat the refrigerant that leaves the test section before it returns to the accumulator tank. The condenser and the sub-cooler are concentric-tube heat exchangers, shown schematically in Figure 5, in whose annular sections chilled water is circulated. The chiller $(\mathrm{CH})$ has a temperature range from -10 to $40^{\circ} \mathrm{C}$, and a volumetric flow rate up to $4.2 \mathrm{l} / \mathrm{min}$. A bypass circuit is also included in order to adjust the average flow rate. The pressure in the test section is measured by means of a pressure transducer, which has a range from 0 to $1 \mathrm{MPa}$. The pressure is regulated varying the temperature and flow rate of water in the condenser.
The input and output temperatures are measured with J-type insulated thermocouples.

Pre-evaporator and evaporator test section design

Figure 6 shows the test section formed by a collinear array of 20 adjacent copper tubes, each having a 3.175 $\mathrm{mm}$ outer diameter, $1.75 \mathrm{~mm}$ inner diameter and $1.5 \mathrm{~m}$ length. The array of tubes is sandwiched between two $90 \mathrm{~cm}$ long, $7 \mathrm{~cm}$ wide and $4.8 \mathrm{~mm}$ thick copper plates. Six J-type thermocouples were inserted along the collinear array in the gaps formed between tubes and the copper plates. In order to reduce the contact thermal resistance, the space between the copper tubes and the plates was filled with conducting silicon paste. Each copper plate is covered with a stainless steel lamina that has 11 cuts, as shown schematically in Figure 7, to form a path for the circulation of an electric current that will generate heat by Joule effect (and will apply it to the system), which is regulated by adjusting the voltage applied with a 0-120 V CA variable autotransformer. A thin gypsum layer is placed as a plank between the copper and 


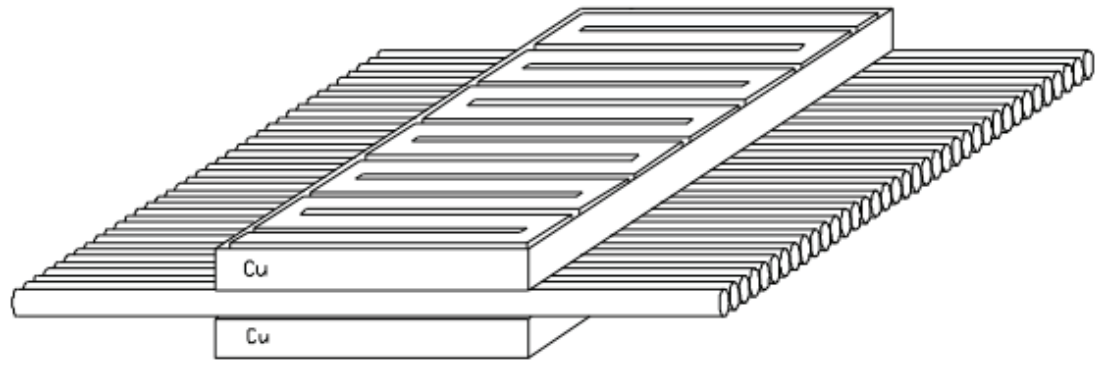

Figure 6 . Schematic of the test section

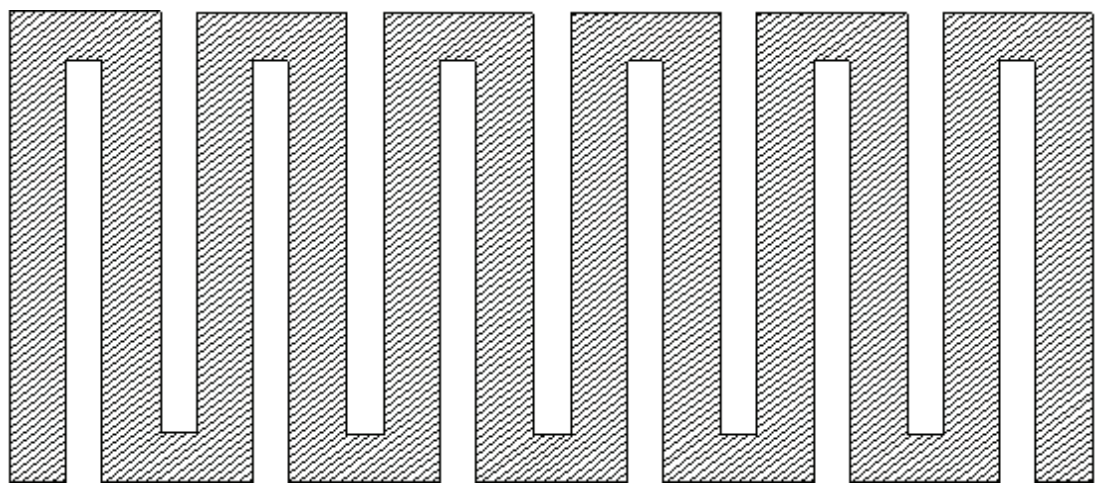

Figure 7. Stainless steel lamina cuts

stainless steel plates to avoid electric currents through the copper plates and tubes. In order to reduce heat losses to the exterior, the outer side of the stainless steel plates is covered with two layers of asbestos tissue and a fiberglass layer.

The information obtained from the experimental runs was collected with a data acquisition system that includes a National Instruments SC-2345 portable modular system, a data acquisition card NI DAQCard6036E for PCMIA, thermocouple modules NI SCC-TC, and a current module NSC-C120. The program Measurement and Automation Explorer is used to obtain data and process them in a PC.

\section{Data collection and processing}

The refrigerant mass flow rate, the system pressure, the applied heat flux generated from the electrical resistance and the incoming refrigerant vapor quality entering the test section were varied during the experiments. The refrigerant mass flow rate was varied by adjusting the operating conditions of the refrigerant pump and the bypass. The system pressure was varied by injection of refrigerant into the system. As indicated above, the magnitude of heat flux applied was varied by adjusting the variable autotransformer position. The vapor quality of the refrigerant entering the test section was controlled by the amount of heat provided in the preevaporator.
The following parameters were measured during the experimental runs:

$T_{s} \quad=$ test section tube surface temperature

$T_{f} \quad=$ average refrigerant temperature during evaporation

$T_{\text {pre }}=$ pre-evaporator refrigerant input temperature

$P \quad=$ system pressure

$\dot{m}=$ refrigerant mass flow rate

$V \quad=$ applied voltage

$I \quad=$ applied current

The temperatures $T_{f}$ and $T_{s}$ are obtained from direct measurements with J-type thermocouples. With these measurements it is possible to calculate the experimental inner flow side convective heat transfer coefficient, $U$, as

$U=U_{r}^{e}=\frac{q^{\prime \prime} A_{p}}{A_{t}\left(T_{s}-T_{f}\right)}$

where $q$ " is the applied heat flux (applied electric power per unit surface area), which is a function of the voltage and current applied and controlled by the variable autotransformer, $A_{p}$ is the copper plates surface area, and $A_{t}$ is the external surface area of the tubes.

The vapor quality at the entrance of the test section was selected to be $20 \%$; this was achieved by regulating the heat provided to the pre-evaporator, which is 
controlled by the variable autotransformer position. The vapor quality at the exit of the test section was selected to be $80 \%$; this was also achieved by regulating the heat provided to the evaporator.

The amount of heat needed to achieve a vapor quality of $20 \%$ as entrance condition to the evaporator, expressed as the product of voltage by current circulated through the pre evaporator, is determined by

$V_{1} I_{1}=\dot{m}\left(h_{2}-h_{1}\right)$

where $h_{2}$ is the enthalpy of refrigerant that is $20 \%$ vapor at the pressure of the test section, and can be determined by $h_{2}=h_{f}+\mathrm{x}_{2} h_{f 8} ; h_{f}$ is the saturated liquid enthalpy of the refrigerant at the evaporator pressure, $h_{f g}$ is the latent heat of evaporation of the refrigerant at the evaporator pressure and $x_{2}$ is the quality, in this case $x_{2}=0.2$.

The amount of heat needed to achieve a vapor quality of $80 \%$ as exit condition of the evaporator, expressed as the product of voltage by current circulated through the evaporator, is determined by

$V_{2} I_{2}=q^{\prime \prime} A_{p}=\dot{m}\left(h_{3}-h_{2}\right)$

where $h_{3}$ is the enthalpy of refrigerant that is $80 \%$ vapor at the pressure of the test section, and can be determined by $h_{3}=h_{f}+x_{3} h_{f g} ; h_{f}$ is the saturated liquid enthalpy of the refrigerant at the evaporator pressure, $h_{f g}$ is the latent heat of evaporation of the refrigerant at the evaporator pressure and $x_{3}$. is the quality, in this case $x_{3}=0.8$.

Table 1. Artificial neural network configurations analyzed

\begin{tabular}{|c|c|c|c|c|}
\hline Inner layers & Configuration & $R$ & $\sigma$ & Maximum error (\%) \\
\hline 1 & $3-3-1$ & 1.0001 & 7.15E-4 & 4.04 \\
\hline 1 & $3-5-1$ & 1.0000 & $6.48 \mathrm{E}-4$ & 3.73 \\
\hline 1 & $3-7-1$ & 1.0001 & $7.00 \mathrm{E}-4$ & 5.52 \\
\hline 1 & $3-9-1$ & 1.0060 & $2.36 \mathrm{E}-3$ & 8.70 \\
\hline 1 & $3-11-1$ & 1.0000 & $6.00 \mathrm{E}-3$ & 3.58 \\
\hline 1 & $3-13-1$ & 1.0000 & $6.89 \mathrm{E}-4$ & 3.67 \\
\hline 2 & $3-1-1-1$ & 1.0001 & $6.98 \mathrm{E}-4$ & 4.51 \\
\hline 2 & $3-3-1-1$ & 1.0000 & $7.00 \mathrm{E}-4$ & 3.70 \\
\hline 2 & $3-5-1-1$ & 1.0000 & $6.83 \mathrm{E}-4$ & 3.73 \\
\hline 2 & $3-5-3-1$ & 1.0000 & $2.90 \mathrm{E}-3$ & 3.80 \\
\hline 2 & $3-5-5-1$ & 0.9970 & $6.70 \mathrm{E}-4$ & 3.80 \\
\hline 2 & $3-6-4-1$ & 1.0000 & $6.25 \mathrm{E}-4$ & 3.70 \\
\hline 3 & $3-1-1-1-1$ & 1.0001 & 7.32E-4 & 4.15 \\
\hline 3 & $3-3-1-1-1$ & 1.0000 & $6.60 \mathrm{E}-4$ & 3.75 \\
\hline 3 & $3-5-1-1-1$ & 1.0001 & 7.14E-4 & 4.01 \\
\hline 3 & $3-5-3-1-1$ & 1.0000 & $6.83 \mathrm{E}-4$ & 3.97 \\
\hline 3 & $3-5-5-1-1$ & 1.0000 & $6.58 \mathrm{E}-4$ & 3.97 \\
\hline 3 & $3-5-5-3-1$ & 1.0000 & 7.01E-4 & 3.98 \\
\hline
\end{tabular}



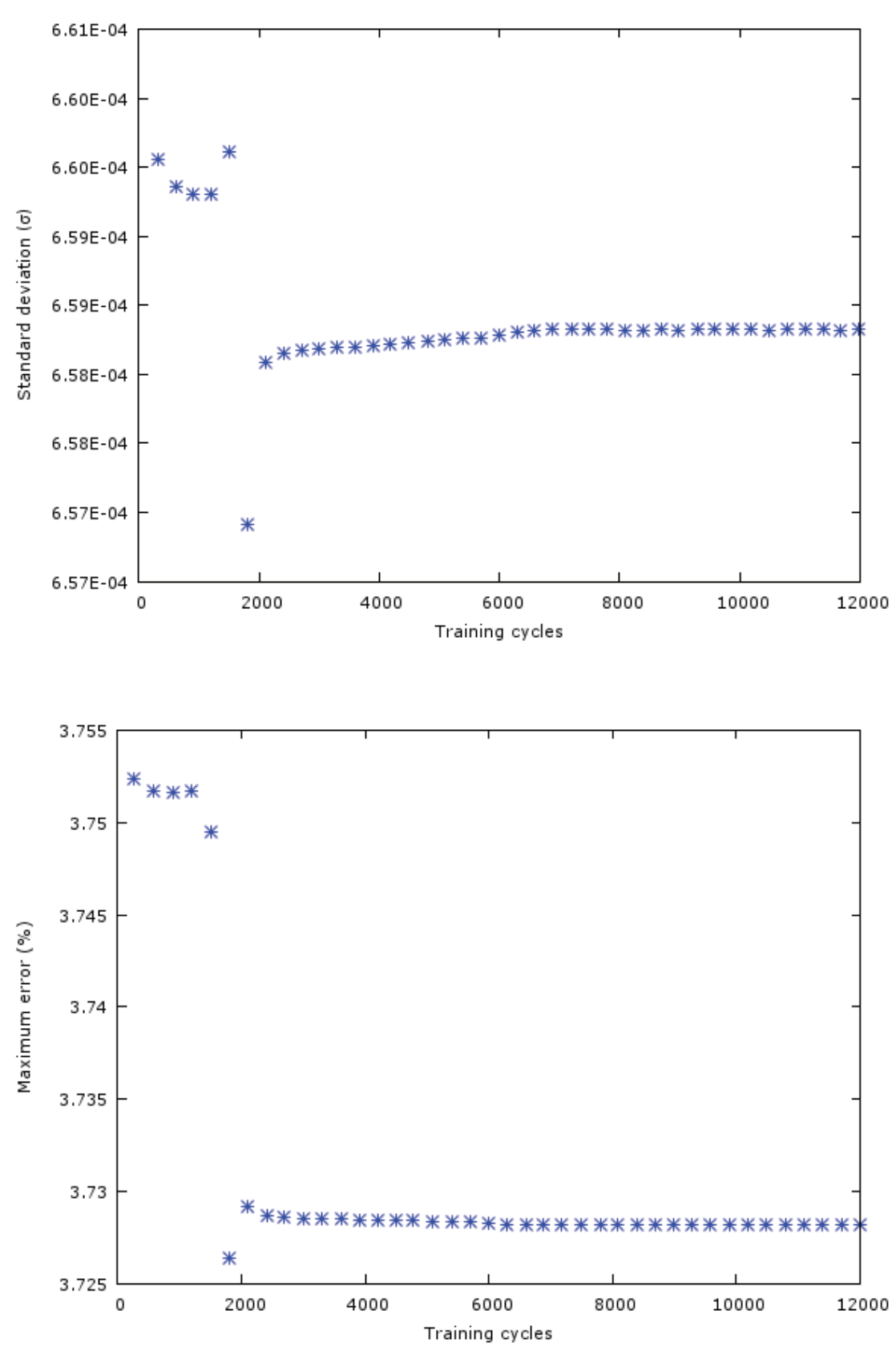

a)

b)

Figure 8. Evolution of a) standard deviation and b) maximum error as a function of the training cycle for the neural network configuration 3-13-1

\section{Results and discussion}

Three parameters were chosen as relevant input data for the characterization of the refrigerant evaporation in the mini-pipe heat exchanger described before. These are: saturation temperature during the evaporation process $\left(T_{\text {sat }}\right)$, refrigerant mass flow rate $(\dot{m})$, and applied heat flux $\left(q^{\prime \prime}\right)$. The output obtained from this information is the experimental convective heat transfer coeffi- cient $\left(U_{r}^{e}\right)$. This combination of parameters is relevant in many cases where the surface temperature adapts to guarantee a given heat flux under a convective heat transfer coefficient condition. The Fortran-77 code used for training the artificial neural network model, and for its subsequent predictions, is a modified version of that developed by Díaz (2000) and Pacheco-Vega (2002). A feature of this new version is that it enables the automatic selection of the most appropriate error function 
(from a pre-defined set), during the training process, for the problem at hand.

A number of 177 measurements of $T_{\text {sat }}, \dot{m}$ and $q$ " were obtained to calculate $U_{r}^{e}$, and 18 different artificial neural network configurations were analyzed and compared to determine the one that provided best predictions of the thermal behavior for the evaporation process. Table 1 shows all the network configurations tested. The number of inner layers, which determine the ANN structure, was set as 1, 2 or 3, with a different number of nodes per layer. For each one of the 18 configurations, the mean value of the ratio between the experimental and predicted transfer coefficients, $R$, the maximum error and the standard deviation, $\sigma$, were calculated during the training process until the maximum number of training cycles was reached. The calculations for $R$ and $\sigma$ were carried out with the following equations

$R=\frac{1}{N} \sum_{r=1}^{N} \frac{U_{r}^{e}}{U_{r}^{p}}$

$\sigma=\frac{1}{N}\left[\sum_{r=1}^{N}\left(\frac{U_{r}^{e}}{U_{r}^{p}}-R\right)^{2}\right]^{1 / 2}$

where $U_{r}^{e}$ is the refrigerant side convective heat transfer coefficient determined from the experimental data and $U_{r}^{p}$ is the convective heat transfer coefficient predicted by the artificial neural network. From the 177 experimental data collected, 133 were used to train each neural network configuration, whereas the remaining 44 datasets were reserved for testing purposes; i.e., for comparison between the experiments and the ANN predictions. Table 1 illustrates the final values of $R$ and $\sigma$ for each configuration. It is to be noted that, following the investigation of Pacheco-Vega et al. (2001a, 2001b), the final neural network model was built with $100 \%$ of the available experimental data, since it allows for the optimum model within the parameter range.

The number of cycles during training was defined in terms of the minimum value of the maximum error and standard deviation. An example of the behavior observed for this error is shown in Figure 8 for the case of the neural network 3-13-1. From the observations of this and other cases not shown in the paper, where the same behavior occurs in all other configurations, it was concluded that after 10,000 cycles the reduction of the maximum error was negligible, and this number of training cycles was taken as the standard throughout this investigation. Importantly, depending on the problem at hand the training process may be computationally expensive but, as pointed out by Pacheco-Vega et al. (2001b), once the ANN has been trained, its subsequent use for predictions is immediate. For the problem at hand, in all cases analyzed the training process took less than 5 minutes of CPU-time per ANN model, which is an excellent processing time as compared to that necessary for the optimization process to find the typical correlation constants. From the table it can be seen that although the results for the 18 configurations are close, the 3-11-1 was the best in terms of the maximum error, while the 3-6-4-1 proved to be the best in terms of $\sigma$. Both configurations are close to the "best" configuration according to the ad-hoc criterion of Hecht (1987), which indicates that the configuration 3-7-1, shown schematically in Figure 9, should be the best. When searching for a more robust model, as mentioned before, there are other configurations that are very competitive. Configuration 3-5-3-1, with $\mathrm{R}=1.0000, \sigma=2.90 \mathrm{E}-4$ and maximum error of 3.80, or configuration 3-3-1-1-1, with $\mathrm{R}=1.0000, \sigma=6.60 \mathrm{E}-4$ and maximum error of 3.75 , are very good options.

Figure 10 shows the convective heat transfer coefficient obtained experimentally, $U_{r}^{e}$, versus the prediction from the neural network 3-3-1-1-1, $U_{r}^{p}$, for each one of the 177 experimental data. It can be seen from the figure that the experimental and predicted values are very close to the ideal straight line that describes the perfect prediction. It is important to mention that the error in the prediction is less than $3.75 \%$, much less than the errors encountered in predictions obtained with correlations that use conventional predictive capabilities. It is evident that neural networks are an excellent tool for prediction of the thermal performance of the evaporation of a refrigerant within a concentric pipe heat exchanger. This fact is further exemplified by using the Liu and Winterton (1991) correlation, which is one of the most accepted for prediction of heat transfer during evaporation of a refrigerant inside flat tubes. Using this

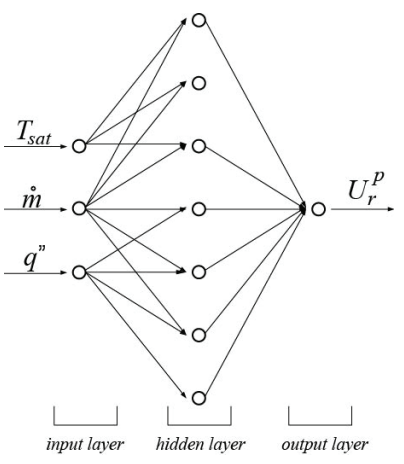

Figure 9. A 3-7-1 neural network configuration analyzed 


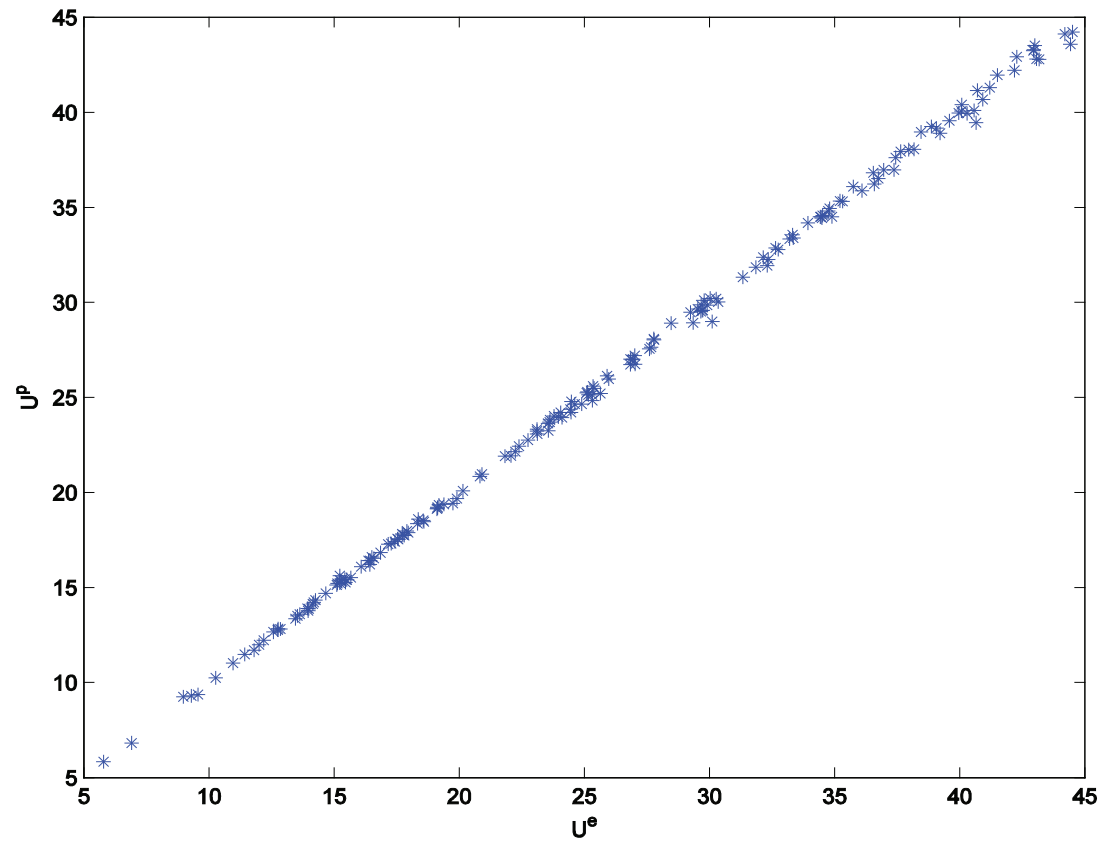

Figure 10. Experimental versus predicted heat transfer coefficient $\left(U_{r}^{e} v s \quad U_{r}^{p}\right)$ for the ANN configuration 3-3-1-1-1 correlation with their own data, the mean error reported between the correlation and the data is $30 \%$. In contrast, the maximum error in the prediction of heat transfer in the present evaporator obtained by the optimal neural network configuration was 3.58\% (the mean quadratic error was $0.6 \%$ ) when compared to our experimental data. Artificial neural networks are a good option for prediction of heat transfer in evaporators with errors of the same order of magnitude as the experimental uncertainty.

\section{Conclusions}

The study of the physics involved in convective evaporation has increased its complexity since the appearance of enhanced surfaces for evaporators and new environmentally-friendly refrigerants. This enhanced complexity has made it more difficult to develop accurate correlations for the prediction of the thermal performance of evaporators. Reports in the literature clearly show that predictions based on models that con- sider forced convection and flooded evaporation as separate phenomena are severely degraded and new alternatives like artificial neural networks (ANNs) are necessary.

We have developed neural network models of a mini-tube evaporator that may be able to accurately predict the thermal performance under several operating conditions. Results obtained using the ANN technique, as developed in this investigation, are very promising. The prediction of heat transfer obtained in this work has a maximum error of $2.46 \%$ and a mean quadratic error of $0.51 \%$, which is by far lower than the $30 \%$ obtained by other authors (Liu and Winterton, 1991), that use conventional correlation techniques. The technique of artificial neural networks is therefore an excellent option for reliable and precise characterization of thermal systems where evaporation processes occur, such as in refrigeration and air conditioning units, and when appropriately trained, the predictions obtained from neural network models are of the order of the experimental uncertainty. 


\section{Nomenclature}

$\begin{array}{clr}\text { ANNs } & \text { Artificial neural networks } & \\ A_{p} & \text { Copper plates surface area, } \mathrm{m}^{2} & q \\ A_{t} & \text { External tube surface area, } \mathrm{m}^{2} & R \\ A T & \text { Accumulator tank } & R \\ C A & \text { Alternating current } & S \\ C H & \text { Chiller } & T_{f} \\ C O & \text { Container } & T_{p} \\ D C & \text { Double pipe condenser } & T \\ D F & \text { Dryer filter } & T \\ E V & \text { Expansion valve } & T \\ F M & \text { Flow meter } & \\ h & \text { Enthalpy, } \mathrm{kJ} / \mathrm{kg} & \\ & & \\ h_{f g} & \text { Latent heat of vaporization, } \mathrm{KJ} / \mathrm{Kg} & \\ I & & \\ \dot{m} & \text { Electrical current, } A & \\ P & \text { Mass flow rate, } \mathrm{kg} / \mathrm{s} & \\ P E & \text { Pressure, } \mathrm{N} / \mathrm{m}^{2} & \end{array}$

\section{References}

Diaz G., Sen M., Yang K.T., McClain R.L. Simulation of heat exchanger performance by artificial neural networks. International Journal of HVAC \& Research, volume 5, 1999: 195-208.

Díaz G.C. Simulation and control of heat exchangers using artificial neural networks, (PhD Thesis), Department of Aerospace and Mechanical Engineering, University of Notre Dame, 2000.

Ermis K., Erek A., Dincer I. Heat transfer analysis of phase change process in a finned-tube thermal energy storage system using artificial neural network. International Journal of Heat and Mass Transfer, volume 50, 2007: 3163-3175.

Ghajar A.J., Tam L.M., Tam S.C. Improved heat transfer correlation in the transition region for a circular tube with three inlet configurations using artificial neural networks. Heat Transfer Engineering, volume 25, 2004: 30-40.

Gungor K.E., Winterton R.H.S. A general correlation for flow boiling in tubes and annuli. International Journal of Heat and Mass Transfer, volume 29, 1986: 351-358.

Hecht-Nielsen R. Kolmogorov's mapping neural networks existence theorem, in: IEEE First International Conference on Neural Networks, pp. iii/11-14, San Diego, 1987.

Hosoz M., Ertunc H.M., Ozguc A.F. Modeling of a direct evaporative air cooler using artificial neural network. International Journal of Energy Research, volume 32, 2008: 83-89.

Islamoglu Y. Modeling of thermal performance of a cooling tower using an artificial neural network. Heat Transfer Engineering, volume 26, 2005: 73-76.

\author{
Peepholes \\ Heat flux, W/ $\mathrm{m}^{2}$ \\ Maximum error \\ Refrigerant pump \\ Sub cooler \\ Temperature of evaporation, ${ }^{\circ} \mathrm{C}$ \\ Pre evaporation inlet temperature, ${ }^{\circ} \mathrm{C}$ \\ Test section \\ Surface tube temperature, ${ }^{\circ} \mathrm{C}$ \\ Saturation temperature \\ Convective heat transfer coefficient, $\mathrm{W} / \mathrm{m}^{2}{ }^{\circ} \mathrm{C}$ \\ Experimental convective heat transfer coefficient, \\ $\mathrm{W} / \mathrm{m}^{2 \circ} \mathrm{C}$ \\ Predicted convective heat transfer coefficient, \\ $\mathrm{W} / \mathrm{m}^{2}{ }^{\circ} \mathrm{C}$ \\ Voltage, Volts \\ Quality \\ Standard deviation
}

Jambunathan K., Hartle S.L., Ashforth F.S., Fontama V.M. Evaluating convective heat transfer coefficient using neural networks. International Journal of Heat and Mass Transfer, volume 39 (issue 11), 1996: 2329-2332.

Kiran T.R., Rajput S.P.S. An effectiveness model for an indirect evaporative cooling (IEC) system: Comparison of artificial neural networks (ANN), adaptive neuro-fuzzy inference system (ANFIS) and fuzzy inference system (FIS) approach. Applied Soft Computing, volume 11, 2011: 3525-3533.

Liu Z., Winterton R.H.S. A general correlation for saturated and subcooled flow boiling in tubes and annuli based on a nucleate pool boiling equation. International Journal of Heat and Mass Transfer, volume 34, 1991: 2759-2766.

Pacheco-Vega A. Simulation of compact heat exchangers using global regression and soft computing, (PhD Thesis), Department of Aerospace and Mechanical Engineering, University of Notre Dame, 2002.

Pacheco-Vega A., Diaz G., Sen M., Yang K.T., McClain R.L. Heat rate predictions in humid air-water heat exchangers using correlations and neural networks. ASME Journal of Heat Transfer, volume 123, 2001a: 348-354.

Pacheco-Vega A., Sen M., Yang K.T., McClain R.L. Neural network analysis of fin-tube refrigeration heat exchanger with limited experimental data. International Journal of Heat and Mass Transfer, volume 44, 2001b: 763-770.

Rumelhart D.E., Hinton G.E., Williams R.J. Learning internal representation by error propagation. Parallel Distributed Processing Explorations in the Microstructure of Cognition, MIT Press, Cambridge, 1986. 
Thibault J., Grandjean B.P.A. Neural network methodology for heat transfer data analysis. International Journal of Heat and Mass Transfer, volume 34 (issue 8), 1991: 2063-2070.

Zdaniuk G.J., Chamra L.M., Walters D.K. Correlating heat transfer and friction in helically finned tubes using artificial neural networks. International Journal of Heat and Mass Transfer, volume 50, 2007: 4713-4723.

Zhao L.X., Yang L., Zhang C.L. Network modeling of fin-and-tube evaporator performance under dry and wet conditions. ASME Journal of Heat Transfer, volume 132 (issue 7), 2010: 074502.

Zhao L.X., Zhang C.L. Fin-and-tube condenser performance evaluation using neural networks. International Journal of Refrigeration, volume 33, 2010: 625-634.

\section{Citation for this article:}

\section{Chicago style citation}

Romero-Méndez, Ricardo, Patricia Lara-Vázquez, Francisco Oviedo-Tolentino, Héctor Martín Durán-García, Francisco Gerardo Pérez-Gutiérrez, Arturo Pacheco-Vega. Use of artificial neural networks for prediction of the convective heat transfer coefficient in evaporative mini-tubes. Ingeniería Investigación y Tecnología, XVII, 01 (2016): 23-34.

\section{ISO 690 citation style}

Romero-Méndez R., Lara-Vázquez P., Oviedo-Tolentino F., DuránGarcía H.M., Pérez-Gutiérrez F.G., Pacheco-Vega A. Use of artificial neural networks for prediction of the convective heat transfer coefficient in evaporative mini-tubes. Ingeniería Investigación y Tecnología, volume XVII (issue 1), January-March 2016: 23-34.

\section{About the authors}

Ricardo Romero-Méndez. Received his B.Sc. in mechanical-electrical engineering from the Universidad Autonoma de San Luis Potosi (Mexico) in 1990. Obtained his M.Eng. in mechanical engineering from the Universidad de Guanajuato (Mexico) in 1993, and his Ph.D. in mechanical engineering from the University of Notre Dame (1998). He has worked in the Department of Mechanical Engineering of the Universidad Autonoma de San Luis Potosi, Mexico, since 1998, where he has been graduate studies coordinator (2000-2008) and planning secretary (2008-2014). Member of the Mexican Researchers System since 1998, where he is currently national researcher level II (2014-2017).

Patricia Lara-Vázquez. Received his B.Sc. in mechanical-electrical engineering from the Universidad Autonoma de San Luis Potosi (Mexico) in 2001. Obtained his M.Eng. in electrical engineering from the Universidad Autonoma de San Luis Potosi (Mexico) in 2004. She has worked in the Universidad Tecnologica de San Luis Potosi since 2006.

Francisco Oviedo-Tolentino. Received his B.Sc. in mechanical engineering, his M.Eng. in mechanical engineering and his Ph.D. in mechanical engineering from the Universidad de Guanajuato (Mexico). He has worked in the Department of Mechanical Engineering of the Universidad Autonoma de San Luis Potosi, Mexico, since 2011. Member of the Mexican Researchers System since 2012, where he is currently candidate (2012-2014).

Héctor Martín Durán-García. Received his B.Sc. in agricultural engineering specialist in agricultural machinery from Universidad Autonoma de Chapingo, M.Eng. in mechanical engineering from Universidad de Guanajuato, his master of farm machinery from University of Tzukuba and his Ph.D. in agricultural engineering from Universidad Politecnica de Madrid. Member of the Mexican Researchers System since 1998, where he is currently national researcher level I (2014-2017).

Francisco Gerardo Pérez-Gutiérrez. Received his B.Sc. in mechanical-electrical engineering from the Universidad Autonoma de San Luis Potosi and his Ph.D. in mechanical engineering from the University of California, Riverside (2010). He has worked in the Department of Mechanical Engineering of the Universidad Autonoma de San Luis Potosi, Mexico, since 2010. Member of the Mexican Researchers System since 2012, where he is currently candidate (20122014).

Arturo Pacheco-Vega. Received his B.Sc. in mechanical-electrical engineering from the Universidad Iberoamericana (Mexico) in 1988, obtained his M.Eng. in mechanical engineering from the Universidad de Guanajuato (Mexico) in 1996, and his Ph.D. in mechanical engineering from the University of Notre Dame in 2002. He was part of the Faculty of Chemical Sciences at the Universidad Autonoma de San Luis Potosi (2003-2008), and since 2008 he has been a faculty member in the Department of Mechanical Engineering of the California State University-Los Angeles. He is a current Member of the Mexican Researchers System, level I (2012-2015). 